\title{
EFEITO DA INCORPORAÇÃO DE EXTRATO PIROLENHOSO EM SUBSTRATO NO DESENVOLVIMENTO INICIAL DE MUDAS DE TOMATE
}

\author{
Julio César Guerreiro ${ }^{1}$ \\ Felipe Santade Bento ${ }^{2}$ \\ Caio Silvestre ${ }^{3}$
}

\begin{abstract}
RESUMO: o objetivo foi avaliar o efeito da incorporação de extrato pirolenhoso (EP) ao substrato de fibra de coco, nas características morfológicas de mudas de tomate. A incorporação do EP se deu 11 dias antes da semeadura da variedade de tomate AP, o trabalho foi constituído de 5 tratamentos com 15 repetições (cada repetição foi constituída de 3 mudas), em um delineamento inteiramente casualizado. Os tratamentos foram: T1 - 0\% de EP; T2 - 0,1\% de EP; T3 - 0,2\% de EP; T4 - 0,4 \% de EP e T5 - 0,6\% de EP. Realizou-se 2 avaliações, uma aos 10 dias após a semeadura (DAS) onde se avaliou comprimento de parte aérea e outra 28 (DAS) que se avaliou comprimento de parte aérea, espessura de caule, peso de matéria seca da parte aérea e peso de matéria seca do sistema radicular. Os dados foram submetidos ao teste de variância (Teste F) e as médias comparadas pelo teste de Tukey. Utilizou-se a análise de correlação para avaliar o crescimento de partes aéreas e radiculares, utilizando o software Estat $\AA^{\circledR}$ - UNESP/FCAV. Observou-se que não houve efeitos negativos no desenvolvimento das mudas. Para as avaliações de comprimento de parte aérea, peso seco do sistema radicular e da parte aérea, destacou-se o tratamento que uso a maior dose ( $0,6 \%$ de EP), por outro lado não houve efeito dos tratamentos na espessura de caule. Tanto para crescimento de parte aérea quanto para peso da parte aérea e sistema radicular observou-se correlação positiva e significativa, entre estes fatores.
\end{abstract}

Palavras-chave: Lycopersicon esculentum; extrato pirolenhoso, características morfológicas.

\footnotetext{
${ }^{1}$ Eng. Agrônomo, Faculdades Integradas de Ourinhos - FIO (Doutor em Entomologia Agrícola). E-mail. juliocguerreiro@yahoo.com.br

${ }^{2}$ Graduando em Agronomia, Faculdades Integradas de Ourinhos - FIO. E-mail.felipesantade@yahoo.com.br

${ }^{3}$ Graduando em Agronomia, Faculdades Integradas de Ourinhos - FIO. E-mail. mauacaio@gmail.com
} 


\section{INTRODUÇÃO}

Segundo Medeiros et al. (2007) são várias as alternativas conhecidas de fertilizantes e defensivos naturais utilizados principalmente na produção de alimentos orgânicos, destacando-se a calda bordalesa, calda sufocálcica e extratos vegetais.

Para Miyasaka e Dulley (1994) os agricultores e pesquisadores têm papel importante na busca por técnicas de aproveitamento de resíduos internos de cada propriedade, para elevar a fertilidade sustentável do solo, assim como desenvolver técnicas pouco agressivas ao meio ambiente.

Dentre os resíduos utilizados pelo homem, destaca-se o extrato pirolenhoso; segundo Campos (2007), a pirólise caracteriza a decomposição térmica de materiais contendo carbono, na ausência de oxigênio. Assim, madeira, resíduos agrícolas, ou qualquer outro tipo de material orgânico durante a queima se decompõe, dando origem a três fases, uma sólida, (carvão vegetal), outra gasosa, e finalmente, a líquida, comumente designada de fração pirolenhosa.

No Brasil a utilização de extrato pirolenhoso (EP) no setor agrícola é recente, no entanto sua aplicação tem sido divulgada e incentivada há algumas décadas. Porém, existem algumas dúvidas sobre a funcionalidade do EP no setor alimentício e agronômico (CAMPOS, 2007).

Segundo Zanetti et al. (2004), o EP é constituído de 800 a $900 \mathrm{~cm}^{3} . \mathrm{dm}^{-3}$ de água e contêm cerca de 200 componentes químicos diferentes, tendo como predominante o ácido acético, o metanol, a acetona e os fenóis. Os compostos fenólicos desempenham várias funções importantes no desenvolvimento de plantas e constituem um grupo quimicamente heterogêneo, com aproximadamente 10.000 compostos (TAIZ e ZEIGER 2009).

Este produto aplicado no solo com mistura em água com a concentração variando de 5 a $20 \mathrm{~cm}^{3} \cdot \mathrm{dm}^{-3}$ melhora suas propriedades físicas, químicas e biológicas, proporcionando o aumento da população de organismos benéficos, como actinomicetos e micorrizas, assim favorecendo a absorção de nutrientes do solo pelo sistema radicular das plantas (MIYASAKA et al., 1999) 
O tomate (Lycopersicon esculentum Mill) pertence à família das Solanaceas que inclui também outras espécies conhecidas, como a batata, o tabaco, os pimentões e a berinjela. É um dos alimentos mais consumidos entre as diversas culturas do mundo, se tornando parte diária da alimentação com significativa quantidade de vitaminas, além de ser fonte comercial importante, com ciclo relativamente curto com cerca 120 dias e de altos rendimentos, para os agricultores. O tomate tem boas perspectivas econômicas e a área cultivada esta aumentando a cada dia devido as suas características nutricionais (NAIKA et al., 2006).

Vários trabalhos científicos como o de Mascarenhas (2006), Schnitzer (2009), Sakita et al. (2007), Porto et al. (2007) e Tashima et al. (2009) têm demonstrado efeitos positivos do EP no crescimento e desenvolvimento de culturas como alface, quiabo, orquídea, angico e pinus.

No entanto, para a cultura do tomate, pouco se sabe sobre o efeito do Extrato Pirolenhoso no desenvolvimento de mudas.

O presente trabalho teve por objetivo avaliar as características morfológicas das mudas de tomateiro (variedade AP), submetidas a diferentes concentrações do extrato pirolenhoso, adicionados ao substrato de plantio.

\section{MATERIAL E MÉTODOS}

O trabalho foi implantado na Estância Hidroceres localizada na rodovia SP 225, Km 319, em Santa Cruz do Rio Pardo. O extrato pirolenhoso na forma líquida utilizado no experimento foi o Piromor, obtido pela carbonização da madeira de Eucalyptus grandis.

Para se testar o efeito do extrato pirolenhoso (EP) no desenvolvimento das mudas de tomateiro, foi realizado o tratamento de substrato comercial de fibra de coco (AMAFIBRA), através da aplicação e incorporação do extrato 11 dias antes da semeadura, conforme recomendação de Miyasaka et al. (2001).

As sementes de tomate utilizadas no experimento foram da variedade AP, semeadas em bandejas de polipropileno com 162 células. Em cada bandeja instalou-se 3 tratamentos e cada tratamento foi repetido 15 vezes, sendo cada repetição composta por 3 mudas. 
A aplicação dos substratos foi constituída de cinco dosagens (tratamentos): T1 0\% de EP; T2 - 0,1\% de EP; T3 - 0,2\% de EP; T4 - 0,4\% de EP; T5 - 0,6\% de EP, em um delineamento Inteiramente casualizado (DIC).

Foram efetuadas duas avaliações a primeira dez dias após a emergência das mudas avaliando altura de mudas e a segunda avaliação foi realizada vinte e oito dias após a emergência, e avaliou-se a altura de mudas, a espessura do caule, peso seco de parte aérea e peso seco de raiz.

Os dados coletados foram submetidos ao teste de variância (Teste $F$ ) e as médias comparadas pelo teste de Tukey $(P \leq 0,05)$. Nesse experimento também foi realizado a análise de correlação para avaliar o crescimento concomitante de parte aérea e do peso da parte aérea e radicular, utilizando o software Estat ${ }^{\circledR}$ - UNESP/FCAV.

\section{RESULTADOS E DISCUSSÃO}

Conforme os resultados observados por Mascarenhas et al. (2006) e Sakita et al. (2007), a incorporação do Extrato Pirolenhoso (EP) ao substrato, em qualquer dos tratamentos estudados, não ocasionou efeito fitotóxico ou falhas no desenvolvimento de mudas de tomate.

De acordo com os dados dispostos na tabela 1, pode-se notar que a aplicação do EP influenciou o crescimento da planta, proporcionando maior desenvolvimento para aquelas que foram semeadas em substrato que tiveram adição de 0,6\% de EP (maior dose do experimento). Observa-se que este efeito foi semelhante nas duas avaliações

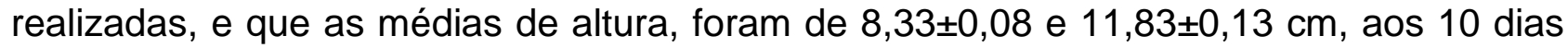
após a semeadura (DAS) e 28 (DAS), respectivamente.

A figura 1 confirma a correlação de desenvolvimento existente entre as mudas de tomate. É possível, portanto, notar que as mudas que apresentaram maior tamanho aos 10 DAS mantiveram seu crescimento proporcional aos 28 DAS, em relação aos demais tratamentos com uma correlação positiva e significativa $\left(t=15,818^{* *} ; r=0,9941 ; p=0,0005\right)$.

Estes resultados são concordantes com as observações realizadas por Schnitzen et al. (2009) para Cattleya intermediata, segundo estes autores o extrato pirolenhoso incorporado ao substrato proporcionou maior altura da parte aérea das plantas. Porém, 
Barbosa et al. (2006) avaliando a altura de inserção da espiga de milho, notou valores menores para tratamentos que utilizaram o EP.

Outro fator avaliado foi a influência do EP na espessura do caule das plantas, notase (Tabela 1) que não houve variação significativa desse fator de acordo com os tratamentos utilizados. Estes dados corroboram com aqueles obtidos por Tashima et al. (2009) que observaram que o extrato pirolenhoso não alterou a espessura de caule de plantas de alface.

Apesar do maior crescimento da parte aérea da planta observado para a maior dosagem, e com espessura de caule semelhante, não foi constado, nesse experimento, o estiolamento das mudas, dessa forma em termos de desenvolvimento de mudas, pode-se indicar a utilização de EP, para a obtenção de mudas mais vigorosas, com a possibilidade de redução do tempo de transplantio.

Tabela 1. Altura média $(\mathrm{cm})$ de mudas \pm erro padrão de tomate aos 10 e 28 dias após a semeadura (DAS), e espessura de caule $(\mathrm{mm}) \pm$ erro padrão aos 28 DAS. Ourinhos, SP, 2012.

Dias Após a Semeadura (DAS)

Tratamentos

(\% de Extrato)

\begin{tabular}{cccc} 
& 10 DAS & 28 DAS & 28 DAS \\
\cline { 2 - 4 } 0 & $7,54 \pm 0,12 \mathrm{a}$ & $11,01 \pm 0,10 \mathrm{a}$ & $2,29 \pm 0,043 \mathrm{a}$ \\
0,1 & $7,76 \pm 0,11 \mathrm{a}$ & $11,21 \pm 0,13 \mathrm{a}$ & $2,31 \pm 0,030 \mathrm{a}$ \\
0,2 & $7,55 \pm 0,13 \mathrm{a}$ & $11,03 \pm 0,13 \mathrm{a}$ & $2,31 \pm 0,051 \mathrm{a}$ \\
0,4 & $7,52 \pm 0,10 \mathrm{a}$ & $11,08 \pm 0,08 \mathrm{a}$ & $2,29 \pm 0,034 \mathrm{a}$ \\
0,6 & $8,33 \pm 0,08 \mathrm{~b}$ & $11,83 \pm 0,13 \mathrm{~b}$ & $2,39 \pm 0,023 \mathrm{a}$ \\
CV (\%) & 5,38 & 3,99 & 6,25 \\
F & $10,22^{* *}$ & $8,75^{\star *}$ & $1,21^{\mathrm{NS}}$ \\
DMS & 0,4264 & 0,4588 & 0,1483
\end{tabular}

** significativo a $1 \%$ de probabilidade pelo teste F; médias seguidas de mesma letra na coluna, não diferem estatisticamente entre si pelo teste de Tukey a $5 \%$ de probabilidade.

Pelos dados dispostos na tabela 2 é possível observar os dados obtidos de peso de matéria seca de parte aérea e sistema radicular. Nota-se, por estas médias, que o 
maior peso de matéria seca de parte aérea foi obtido no tratamento em que foi utilizada a

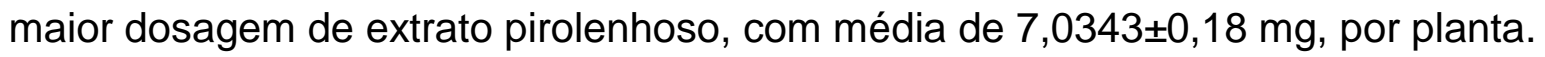

Da mesma maneira, pode-se notar maior peso radicular no tratamento que se

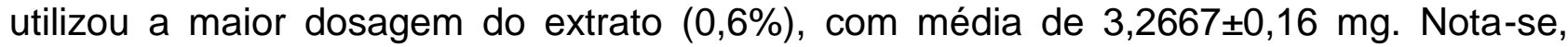
porém, que esta média não se diferenciou das obtidas nos demais tratamentos em que foi utilizado qualquer dose de EP, aplicados aos substratos.

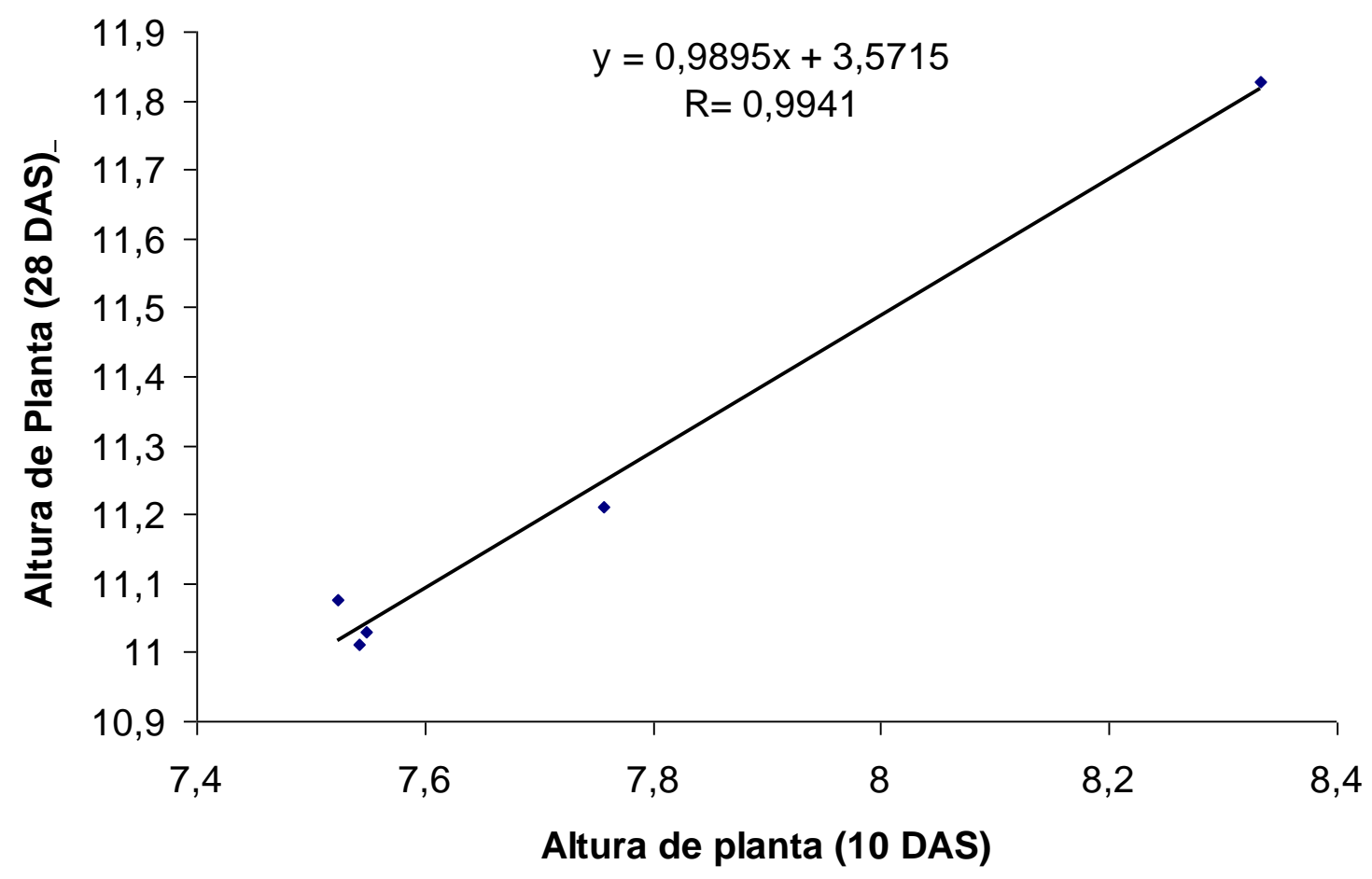

Figura 1. Correlação de alturas de plantas $(\mathrm{cm})$ aos 10 e 28 dias após a semeadura (DAS). Ourinhos, SP, 2012.

Essa tendência de aumento de peso da matéria seca de parte aérea e radicular foi observado por Mascarenhas et al. (2006) para alface e por Porto et al. (2007) para Pinnus elliottii, segundo estes autores, em todos os tratamentos em que se utilizou EP obteve-se maior alongamento radicular e desenvolvimento de raízes secundarias.

De acordo com os dados demonstrados na figura 2, é possível observar que o aumento do peso da parte aérea de mudas do tomateiro pôde ser correlacionado com o aumento do peso da matéria seca do sistema radicular ( $\left.t=4,755^{* *} ; r=0,9396 ; p=.0,0005\right)$. 
Como pode ser observado por estes dados (Tabela 2 e Figura 2), o EP pode influenciar o desenvolvimento morfológico de plantas, alterando o crescimento de muda e sua arquitetura de forma positiva, implicando na formação de partes aéreas e radiculares mais vigorosas e desenvolvidas.

Tabela 2. Peso de matéria seca de arte aérea e radicular $(\mathrm{mg})$ de mudas \pm erro padrão de tomate aos 28 dias após a semeadura (DAS). Ourinhos, SP, 2012.

Tratamentos

(\% de Extrato)
Matéria seca de plantas $(\mathrm{mg})$

\begin{tabular}{cc}
\hline Parte aérea & Parte radicular \\
\hline $6,0875 \pm 0,17 \mathrm{a}$ & $2,7778 \pm 0,10 \mathrm{a}$ \\
$6,1572 \pm 0,12 \mathrm{a}$ & $2,9622 \pm 0,16 \mathrm{ab}$ \\
$6,0863 \pm 0,10 \mathrm{a}$ & $2,8996 \pm 0,10 \mathrm{ab}$ \\
$6,1037 \pm 0,12 \mathrm{a}$ & $2,7926 \pm 0,08 \mathrm{ab}$ \\
$7,0343 \pm 0,18 \mathrm{~b}$ & $3,2667 \pm 0,16 \mathrm{~b}$ \\
8,63 & 16,04 \\
$8,75^{\star *}$ & $2,65^{\star}$ \\
0,5558 & 0,4826
\end{tabular}

${ }^{* *}$ significativo a $1 \%$ de probabilidade pelo teste $\mathrm{F}$; médias seguidas de mesma letra na coluna, não diferem estatisticamente entre si pelo teste de Tukey a $5 \%$ de probabilidade.

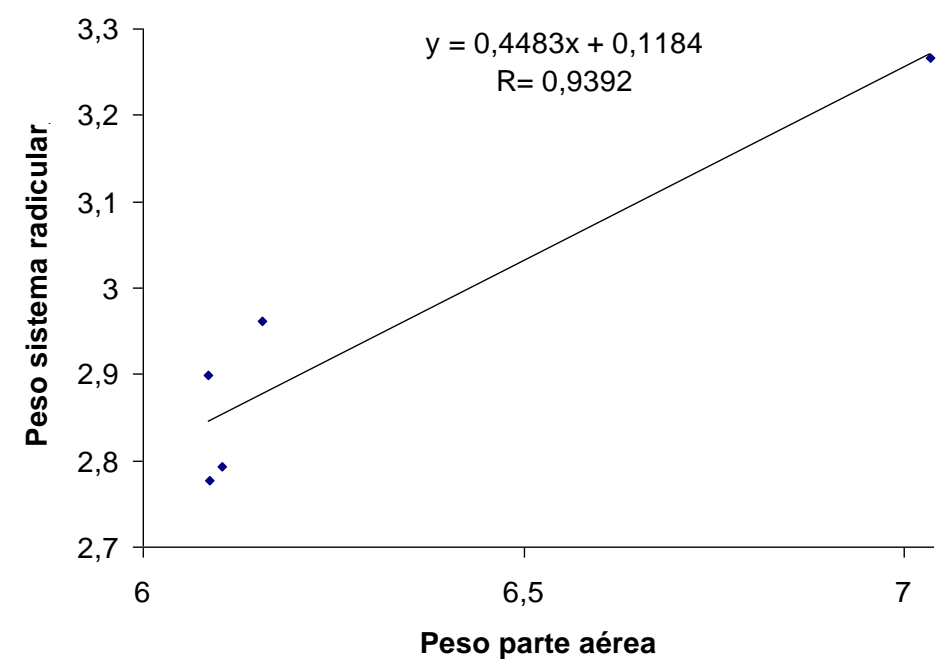

Figura 2. Correlação do peso $(\mathrm{mg})$ entre parte aérea e sistema radicular de mudas de tomate. Ourinhos, SP, 2012. 
Esse comportamento positivo do desenvolvimento das mudas evidencia grande vantagem no momento do transplantio, favorecendo uma melhor adaptação e um melhor desenvolvimento inicial da planta ao meio onde será realizado o transplantio.

Além dos fatores positivos observados pelo EP com o desenvolvimento morfológico de mudas, o resultado desse trabalho evidencia uma forma de destinação segura e prática para esse resíduo, que segundo Campos (2007) é obtido em grandes quantidades da pirolise de materiais que contenham carbono como fórmula estrutural.

\section{CONCLUSÃO}

Não houve qualquer tipo de efeito fitotóxico da utilização do extrato pirolenhoso em mudas de tomate;

O extrato pirolenhoso incorporado ao substrato de fibra de coco, proporcionou desenvolvimento positivo das mudas, influenciando o tamanho da planta e peso de parte aérea e sistema radicular.

\section{REFERÊNCIAS}

BARBOSA, F.A.G.; HERMANN, E. R. Efeito de doses do extrato pirolenhoso na cultura do milho. In: I Fórum de biotecnologia do Vale do Paranapanema - Novos rumos para o desenvolvimento.(Anais) 2006. UNESP- Universidade Estadual Paulista "Júlio de Mesquita Filho", Assis, 2006. 75p.

CAMPOS, A. D. Técnicas para a produção de Extrato Pirolenhoso para Uso Agrícola. Circular Técnico, Pelotas-RS, n. 65 Embrapa, 2007.

DULLEY, R, D.; MIYASAKA, S. Agricultura sustentável e prioridade aos insumos agrícolas internos. Informações Econômicas, v.24, n.11, 1994.

MASCARENHAS, M. H. T.; LARA, J. F. R.; PURCINO, H. M. A.; SIMÕES, J. C.; MOREIRA, D. C.; FACION, C. E. Efeito da utilização do extrato pirolenhoso na produtividade do alface. Revista Brasileira de Horticultura, Goiânia, v. 24, n. 1, p. 31223125, 2006.

MEDEIROS, D. D.; SILVA FILHO, J. C. G.; CALABRIA, F. A. et al. Aplicação da produção mais limpa em uma empresa como ferramenta de melhoria contínua. São Paulo, Produção, 2007. 
MEDEIROS, M. B.; SANTOS, D.; BARBOSA, A. S.; Produtos trofobióticos na proteção de plantas. Ver. Bras. De Agroecologia, V.2, n.2, 2007.

MIYASAKA, S.; OHKAWARA, T.; NAGAI, K.; YAZAKI, H.; SAKITA, M.N. Técnicas de produção e uso do Fino de Carvão e Licor Pirolenhoso. In: I Encontro de Processos de Proteção de Plantas - Controle ecológico de pragas e doenças (Anais), Botucatu, APAN, p.161-176, 2001.

MIYASAKA, S.; OHKAWARA, T.; UTSUMI, B. Acido pirolenhoso: uso e fabricação. Boletim Agroecológico, n. 14, 1999.

Naika, S.; Jeude, J. V. L.; Goffau, M.; Hilmi, M.; Dam, B. V. A cultura do Tomate, produção, processamento e comercialização. Agrodok 17, 2006.

PORTO, P. R.; SAKITA, A. E.N.; SAKITA, M.N. Efeito da aplicação do extrato pirolenhoso na germinação e no desenvolvimento de mudas de Pinus elliotti variedade elliotti. IF Série Registros, São Paulo, n. 31, p. 15-19, 2007.

SAKITA, A. E.N.; PORTO, P. R.; SAKITA, M.N. Utilização do Extrato Pirolenhoso na germinação e no desenvolvimento inicial de mudas de Anadenanthera macrocarpa (Benth.) Brenan. IF Série Registros, São Paulo, n. 31, p. 57-61, 2007.

SCHNITZER, J. A. Extrato Pirolenhoso no Cultivo de Orquídeas. 2009. 60f. Tese (PósGraduação), Universidade Estadual de Londrina, Londrina, 2009.

SCHNITZER, J. A.; FARIA, R. T.; VENTURA, M. U.; SORACE, M. Substratos e extrato pirolenhoso no cultivo de orquídeas brasileiras. Acta Scientiarum Agronomy, Maringá, 2009.

TAIZ, L.; ZEIGER, E. Fisiologia Vegetal. 4ํe edição. Porto Alegre, Artmed, 2009.

TASHIMA, H.; HASEGAWA, M.; REIS, T. S.; CHRIST, T. O. A.; RODRIGUES, W. H.; NISHIDA, C. M.; MAYER, C. M.; RODRIGUES, L. B. Aplicação do Extrato Pirolenhoso na Cultura da Alface. In: II Simpósio de Engenharia Rural, Bandeirantes-PR, 2009.

ZANETTI, M.; CAZETTA, J. O.; JUNIOR, D. M.; CARVALHO, S. A. Influência do extrato pirolenhoso na calda de pulverização sobre o teor foliar de nutrientes em limoeiro Cravo. Ver. Bras. Frutic, Vol.26, n.3, Jaboticabal, 2004. 